\title{
Death Anxiety, Depression, and Coping in Family Caregivers
}

\author{
Veronica Semenova \\ Walden University \\ Lee M. Stadtlander \\ Walden University
}

\begin{abstract}
Along with the increase in elderly patients with chronic and disabling conditions, the number of family caregivers continues to rise. Caregiving has been associated with negative physical and psychological impact on the caregivers' health, as well as, with higher prevalence rates of depression, anxiety, and a higher risk of mortality. The purpose of this study was to examine if death anxiety would be a significant predictor of depression and coping in the sample of adult family caregivers of adult patients. Participants were 46 family caregivers recruited through caregiver websites. Participants completed the Revised Collett-Lester Fear of Death and Dying Scale, the Center for Epidemiological Studies Depression ScaleRevised, the Ways of Coping Questionnaire, and a demographic questionnaire. Multiple regression analysis identified significant relationships between death anxiety, depression, coping, and duration of caregiver experience. The findings of this study provide medical practitioners and psychologists with enhanced knowledge, facilitating development of interventions to help family caregivers deal with death anxiety and achieving efficient coping.
\end{abstract}

Keywords: caregiving, caregiver depression, death anxiety, fear of death, caregiver coping, family caregivers

\section{Introduction}

Family caregiving is the primary method of long-term care delivery around the world. In the United States, about 65.7 million family caregivers provide millions of hours of assistance valued at $\$ 450$ billion in 2009 for an average of 4.6 years (AARP Public Policy Institute, 2011; Family Caregiver Alliance, National Center on Caregiving [FCA], 2011; National Alliance for Caregiving \& AARP, 2009). Family caregivers provide unpaid help to a relative (e.g., spouse, significant other, parent, child, or other family member) incapable of performing the daily living tasks due to a medical condition or advanced age (FCA, 2011). The World Health Organization (2010) estimates that there will be 1.2 billion people over age 60 by 2025 and 2 billion people by 2050 . Rapid growth of the aging population, the associated increase of patients with chronic conditions requiring home care, and advances in medicine have extended patients' lives. This shift of care from institutional to homebased will inevitably continue to increase the number of family caregivers in a home setting.

The term family caregiver refers to an unpaid relative who provides help to the patient incapable of performing daily living tasks (National Alliance for Caregiving \& AARP, 2009). Illnesses such as stroke, cancer, Alzheimer's disease, Parkinson's disease, traumatic brain injury, AIDS, childhood

Please address queries to: Veronica Semenova, P.O. Box 52355, 4063 Limassol, Cyprus. Email:

semenova.veronica@gmail.com

This paper is based upon the first author's doctoral dissertation. She would like to acknowledge the support of her dissertation committee: Drs. Virginia Salzer, Lee M. Stadtlander, and Jennifer Plebani. 
muscular dystrophy, developmental disorders, various forms of disability, or simply very old age, all require family caregiving. The average duration of a caregiver's role is 4.6 years, with $34 \%$ of caregivers reporting caring for their ill relative for 1 to 4 years, 31\% caring for them 5 or more years, and $15 \%$ caring for 10 or more years (FCA, 2011).

\section{Effects of Caregiving on the Caregiver}

Caring for the ill loved one results in serious implications for the caregiver, including increased financial, emotional, and physical burdens. Caregivers face restrictions in their social life leading to isolation, as well as reduced or lost employment (Brazil, Bainbridge, \& Rodriguez, 2010; FCA, 2011). As many as $70 \%$ of working caregivers reported suffering work-related difficulties, with $12 \%$ having to reduce work hours and $9 \%$ being forced to give up work completely (FCA, 2011).

Family caregiving affects caregivers' physical health; the negative effects of caregiving on the health of caregivers have been established by many researchers in the past 2 decades. Caregiving has been associated with a decline in immune function (Glaser \& Kiecolt-Glaser, 2005; Murphy, Christian, Caplin, \& Young, 2007), cardiovascular changes such as hypertension (Vitaliano \& Katon, 2006), development and progression of many illnesses (Lovell \& Wetherell, 2011), and increased mortality (Glaser \& Kiecolt-Glaser, 2005; Hauser \& Kramer, 2004; Lovell \& Wetherell, 2011; Schulz \& Beach, 1999; Waldrop, Kramer, Skretny, Milch, \& Finn, 2005). Negative health effects are caused by the lack of time to devote to self-care and negligence of protective health behaviors (such as maintaining a healthy diet, exercising routinely, keeping medical appointments, and getting adequate sleep) due to the caregiving burden. In addition, caregiver depression has been associated with severe weakening of the immune system in a number of studies (Vedhara \& Irwin, 2005).

\section{Psychological Distress in Caregivers}

Many caregivers face severe psychological distress (Cassidy, 2011; Cassidy \& McLaughlin, 2015; Pinquart \& Sorensen, 2003; Pinquart \& Sorensen, 2011). Anticipation of a negative patient outcome, anticipatory grief, emotional distress from watching their loved ones suffer from pain as they weaken and deteriorate, inability to change the course of events, feelings of guilt, resentment, and disappointment all have a profound impact on caregivers' mental health (Waldrop et al., 2005). Often, caregivers also need to deal with the patient's verbal and physical aggression, confusion, and anger, which may accompany some dementia and terminal cancer conditions (Pinquart \& Sorensen, 2003). Coping with such intense emotional stressors and anticipatory grief becomes a necessary adjustment in the life of the patient's family members (Cassidy \& McLaughlin, 2015).

Depression is one of the most common conditions suffered by caregivers (Brazil et al., 2010; Rivera, 2009; Smith, Williamson, Schulz, \& Miller, 2011). Among family caregivers, $40 \%$ to $70 \%$ experience clinical symptoms of depression (FCA, 2011), which may manifest as an emotional reaction to the caregiving stress (Rivera, 2009; Smith et al., 2011). Depression in caregivers may contribute to anticipatory grief and vice versa (Holley \& Mast, 2010).

Caregivers suffering from depression are at higher risk for complicated grief and further worsening of depressive symptoms during bereavement (Holtslander \& McMillan, 2011). Studies have found an association between depression and weakening of the immune system (Vedhara \& Irwin, 2005); caregiver depression produces a negative impact on health and may contribute to higher mortality (Rivera, 2009; Smith et al., 2011). 
Mental health care providers and researchers have been interested in how the impact of caregiving varies for individual family caregivers. For some family caregivers, caregiving leads to serious mental health consequences. Yet other caregivers with similar responsibilities cope well and manage to avoid or minimize the detrimental effects of caregiving. Some research suggests that personal value and belief systems of the family caregivers may influence the level of psychological distress (Carver \& Connor-Smith, 2010; Tew, Naismith Pereira \& Lewis, 2013). Other studies have suggested that the choice of becoming a caregiver is an important factor (Pinquart \& Sorensen, 2003; Pinquart \& Sorensen, 2011).

\section{Coping}

Coping is the behavioral and cognitive efforts used by individuals as they try to minimize the effects of stress (Lazarus \& Folkman, 1984). Coping is a conscious, process-oriented effort and involves using specific skills to manage stress (Lazarus \& Folkman, 1984). Coping can be adaptive, which reduces stress levels or maladaptive, which increases stress levels. Coping can also be reactive, leading to an action taken in response to the stressor, or proactive, leading to an action to minimize effects of the future stressor. Coping can be influenced by personal characteristics such as age, gender, education, as well as social and environmental factors (Carver \& Connor-Smith, 2010; Raggia, Tascab, Paneraib, Neria, \& Ferrib, 2015).

Caregivers use coping strategies to adjust to the changing life events and to manage the illness of the patient under their care (Cassidy \& McLaughlin, 2015). Measuring the efficacy of caregivers' coping involves identifying what coping strategies the particular caregiver uses. These strategies can range between appraisal-focused, problem-focused, and emotion-focused strategies (Lazarus \& Folkman, 1984). There are positive aspects in each type of coping strategy. Couper et al. (2006) reported that caregivers using problem-solving strategies demonstrated lower levels of distress than caregivers who used appraisal- or emotion-focused coping strategies. Kelly et al. (1999) reported that strategies such as denial and avoidance lead to greater strain in coping. Greater caregiver strain is associated with maladaptive coping strategies that include "avoidance, passivity, self-blame, and resignation" (Redinbaugh, Baum, Tarbell, \& Arnold, 2003, p. 903). Confidence in their coping abilities allows caregivers to demonstrate better psychological adjustment (Cassidy, 2011).

\section{Death Anxiety}

Being in close contact with the patient and watching his or her physical deterioration and pain may awaken family caregivers' own fears of death and dying (Yalom, 1980). Death anxiety is a fundamental fear and is theorized to be one of the major components of the existential beliefs of every individual (Neimeyer, 1994). Constant awareness of one's own mortality may be elevated in critical times or stages of one's life. During the course of a lifetime, there are several critical stages and events that may trigger a stronger sense of death anxiety, such as retirement, death of a close relative, and major milestone birthdays such as 60 or 70 (Yalom, 1980). Moore and Williamson (2003) noted that fear of death is a natural reaction to confrontation with death. Caregivers may directly or indirectly be more likely to experience this type of anxiety. There are a few studies examining death anxiety in caregivers (e.g., Bachner, O’Rourke, \& Carmel, 2011; Neimeyer, Wittkowski, \& Moser, 2004). Caregivers who express greater death anxiety are less accepting of the patient's impending death; on the other hand, caregivers who demonstrate death acceptance tend to be capable of acknowledging their own mortality (Bachner et al., 2011; Neimeyer et al., 2004). The 
inability to accept the impending death of the patient could lead to less ability to cope with caregiver stress.

Caregivers face substantial barriers discussing the illness and impending death with the patient (Bachner \& Carmel, 2009). Death and dying are the most difficult issues to discuss for terminal patients and their caregivers (Zhang \& Siminoff, 2003). Bachner, Davidov, and Carmel (2008) suggested that caregivers and patients may enter a mutual protective buffering communication to avoid discussing fears and death-related issues in an effort to protect each other.

There are many studies of death anxiety in the elderly (Fortner \& Neimeyer, 1999; Fortner, Neimeyer, \& Rybarczyk, 2000; Missler et al., 2011; Neimeyer et al., 2004; Wagner \& Lorion, 1984; Wink, 2006). Contrary to the common belief that death anxiety increases as the person nears the end of life in old age, no association has been found; Feifel and Nagy (1980) reported that the elderly tend to report lower levels of death anxiety than younger adults. Death anxiety is associated with having physical problems, psychological distress, weaker religious beliefs, and lower ego integrity, life satisfaction, and resilience (Fortner \& Neimeyer, 1999). Gender and age do not tend to be related to death anxiety (Fortner et al., 2000); however, Lester (1994) reported that women demonstrated higher levels of death fear than men. Fear of losses and aging anxiety are consistent predictors of death anxiety (Benton, Christopher, \& Walter, 2007). Spirituality is a significant predictor of reduced fear of death (Harrawood, 2009-2010; Wink, 2006), and spiritual experiences help individuals deal with their death anxiety (Kuhl, 2005).

Death anxiety has been associated with a variety of psychopathological morbidities, including anxiety, obsessive-compulsive disorder, depression, hypochondriasis, agoraphobia, and serious health threats due to the weakening of the immune system (Barr \& Cacciatore, 2008; Furer \& Walker, 2008; Hintze, Templer, Cappelletty, \& Frederick, 1994; Neimeyer et al., 2004; O’Gorman, 1998). The relationship between depression and death anxiety mostly in the elderly population, bereaved individuals, and HIV patients has been confirmed in a number of studies, with depression found to be a strong predictor of death anxiety (Barr \& Cacciatore, 2008; Hintze et al., 1994; Lonetto \& Templer, 1986; Neimeyer, 1994; O’Gorman, 1998; Wagner \& Lorion, 1984). Research on death anxiety in caregiving has primarily addressed professional caregivers, such as physicians, hospice workers, and nurses (Sharif Nia, Lehto, Ebadi, \& Peyrovi, 2016).

The relationship between caregiving and depression has also been extensively researched (Smith et al., 2011). Lazarus and Folkman (1984) suggested that person-specific beliefs play a major role in determining response to threatening life situations. The lack of research into the relationship between death anxiety and coping clearly reveals a need to explore the relationship between death anxiety, coping, and depression in family caregivers.

\section{Theoretical Framework of Coping}

Lazarus and Folkman (1984) developed the transactional theory of stress. It is an interpersonal approach to coping and adjustment, which states that coping is a process during which an individual forms an appraisal of the stressor, responds to the stressor with an action, and then reevaluates the stressor. Caregivers use coping strategies to accept the illness of the patient under their care and learn to adjust to the changing events in their lives. Adaptive problem-focused coping strategies can also prepare caregivers to deal with anticipatory grief. By using adaptive coping strategies, caregivers are able to minimize the negative effects of caregiver distress and burden (Cassidy, 2011; 
Redinbaugh et al., 2003). Confidence in coping abilities allows caregivers to demonstrate better psychological adjustment (Cassidy, 2011). For example, Redinbaugh et al. (2003) examined 31 pairs of hospice patients and their family caregivers and found that caregivers who accepted the patient's illness, came to terms with illness-related problems, and maintained confidence in being able to deal with upcoming problems demonstrated lower levels of caregiver strain.

The current study examined if death anxiety would be a significant predictor of depression and coping in a sample of adult family caregivers of adult patients. The research questions were whether death anxiety could predict depression and coping in family caregivers and whether death anxiety is related to participant demographics. The study examined family caregivers to adult patients only, as caregiving of children may be influenced by other factors and explained through other theories, given the emotionality of the bond between children and their parents. The study also did not focus on caregivers of patients with a specific illness (such as Alzheimer's disease or cancer) and, rather, attempted to establish a general association of the examined variables in caregiver experience. The primary investigator's Institutional Review Board approved this study (Approval \#06-13-120081857).

\section{Method}

\section{Participants}

The convenience sample included individuals currently involved in family caregiving of adult patients or those who have been involved in family caregiving in the last 5 years. To participate in the study, the caregiver and the patient under care needed to be over 18 years old and fluent in reading English. Invitations to participate in the study were posted on several caregiver resource websites. The study was hosted on SurveyMonkey.com.

To conduct multiple regressions with two predictor variables and the goal of obtaining a power of .80, this study used an alpha level of .05 and a medium effect size of .26. The recommended sample size was determined to be 40 participants. The final sample consisted of 46 participants between the ages of 24 and $78(M=56.43, S D=11.25)$. The majority of participants were females $(89.1 \%, n=41)$ and 10.9\% $(n=5)$ were males. Approximately $78 \%(n=36)$ were European American, $9 \%(n=4)$ were African American, 9\% $(n=4)$ were Latinos/Hispanics, and 4\% $(n=2)$ did not answer the question about race. The sample achieved represents the general caregiver population. In contrast, the average age of caregivers in the United States is 48 years old, with $66 \%$ of caregivers being female, $72 \%$ of caregivers reported themselves as European American, $13 \%$ as African American, and $12 \%$ as Latinos/Hispanics (National Alliance for Caregiving \& AARP, 2009).

The majority of caregivers in the study $(60.9 \%, n=28)$ were married, $17.4 \%(n=8)$ were living with their partners, $10.9 \%(n=5)$ were divorced or separated, $6.5 \%(n=3)$ were widowed, and $4.3 \%(n=2)$ were single. Approximately 35\% $(n=16)$ of caregivers had bachelor's degrees, $32.6 \%(n=15)$ had master's degrees, $15.2 \%(n=7)$ had completed some college, $13 \%(n=6)$ had graduated high school, and $4.3 \%(n=2)$ had doctoral degrees . Regarding country of residence, $91.3 \%(n=42)$ were from the United States, whereas Belgium (2.2\%), Mexico (2.2\%), and the Russian Federation (2.2\%) each had one participant. One participant did not answer this question. Relative to geographic location in the United States, California had the largest number of participants $(15.2 \%, n=7)$, followed by Maryland $(8.7 \%, n=4)$, Illinois $(6.5 \%, n=3)$, and Florida $(6.5 \%, n=3)$. Other states represented in the sample included Alabama, Arizona, Georgia, Hawaii, Idaho, Kansas, Kentucky, Maine, 
Michigan, Minnesota, Nebraska, Nevada, New York, North Carolina, Oregon, Pennsylvania, Tennessee, Texas, Virginia, and Wisconsin.

\section{Rationale}

The current study examined whether death anxiety would be a significant predictor of depression and coping in the sample of adult family caregivers of adult patients and if participant demographics would be significant predictors of death anxiety. There were two primary research questions for the study. (a) Can death anxiety predict depression and coping in family caregivers? (b) How do scores on the Revised Collett-Lester Fear of Death and Dying Scale (RCL-FODADS) relate to participant demographics (age, gender, education level, number of children, relationship to patient, and duration of caregiver experience)?

\section{Instrumentation}

\section{Death Anxiety}

The RCL-FODADS (Lester, 1994) is a 32-item scale on which the items are separated into four subscales, with eight items each. The scale assesses the individual's attitudes to his or her own death, own dying, death of others, and dying of others. The main distinction of the RCL-FODADS from other measures of death anxiety is that it allows distinguishing between the fear of death and the fear of dying and between fears of own death and dying from the fears of death and dying of the others (Lester, 1994). Respondents are required to indicate the extent to which they are disturbed or made anxious by different aspects of death and dying on a 5-point scale from very through somewhat to not. The statements include items such as "I would not feel anxious in the presence of someone I knew was dying." A total score is derived by summing the scores for each item, yielding a maximum score of 40 for each subscale. The scale demonstrates internal consistency (Cronbach's $\alpha$ ) of 0.91 for Fear of Death of Self, 0.89 for Fear of Dying of Self, 0.72 for Fear of Death of Others, and 0.87 for Fear of Dying of Others (Lester, 1994). Two-day test-retest reliability was 0.85 for Fear of Death of Self, 0.79 for Fear of Dying of Self, 0.86 for Fear of Death of Others, and 0.83 for Fear of Dying of Others (Lester, 1994). The fears of death and dying from the RCL-FODADS correlate significantly with neuroticism for both women and men and extraversion for men (Lester, 1994).

\section{Depression}

The Center for Epidemiological Studies Depression Scale-Revised (CESD-R; Eaton, Ybarra, Muntaner, \& Tien, 2004) is a 20-item scale that was initially developed by Radloff (1977) to screen for depression in the general population. Respondents are required to indicate how often they have felt this way in the past week or so on a 5-point scale with scores of 0 (not at all or less than 1 day), 1 (1-2 days), 2 (3-4 days), 3 (5-7 days), and 4 ( nearly every day for 2 weeks). The statements include items such as "I had trouble keeping my mind on what I was doing." Scores range from 0 to 80 , with the higher score indicating greater depression levels. The mean score of the CESD-R was 31.0. Scores above 16 indicate depressive symptomatology. The scale has been tested using personal interview, paper, telephone, and the Web and has a well-proven validity and reliability. The scale demonstrates internal consistency (Cronbach's $\alpha$ ) of 0.89 and excellent test-retest reliability (Eaton et al., 2004).

\section{Coping}

The Ways of Coping Questionnaire (WCQ) was developed by Lazarus and Folkman (Lazarus \& Folkman, 1984; Folkman \& Lazarus, 2005) and represents a 66-item scale, measuring thoughts and 
acts used by people dealing with internal and/or external stressors. The WCQ consists of the eight subscales measuring coping processes, including Confrontive Coping, Distancing, Self-Controlling, Seeking Social Support, Accepting Responsibility, Escape-Avoidance, Planful Problem Solving, and Positive Reappraisal. Items have been designed to be answered thinking about a specific stressful situation. Respondents are required to indicate the extent to which they used each of the proposed actions in the stressful situation from 0 to 3 with responses of 0 (does not apply or not used), 1 (used somewhat), 2 (used quite a bit), and 3 (used a great deal). Subscale scores range from 0 to 30 for all subscales with higher scores, indicating greater use of coping strategy (Kieffer \& MacDonald, 2011). The statements include items such as "I turned to work or another activity to take my mind off things" and "I went on as if nothing had happened." Lazarus and Folkman (1984) reported internal consistency reliabilities across the eight scales ranging from .61 to .79.

In this study, instrument reliability was examined with Cronbach's alpha. The internal consistency of the CESD-R was .928. Cronbach's alpha for the WCQ was .903 for all items. The RCL-FODADS had a reliability coefficient of .927 for all items.

\section{Demographic Questionnaire}

The demographic questionnaire collected information about age, gender, race, religion, marital status, number of children, and education. In addition, the questionnaire gathered details of caregiver experience, including the relationship to the patient, the nature of patient's diagnosis, the duration of caregiving so far or in total (if patient died in the last 5 years), and whether or not the patient shared fears or feelings about the illness or death and dying with the caregiver.

\section{Results}

The single most frequent patient diagnosis was cancer $(26.1 \%, n=12)$, followed by Alzheimer's disease $(23.9 \%, n=11)$ and dementia $(8.7 \%, n=4)$. Low-incidence diagnoses included renal failure $(4.3 \%, n=2)$, traumatic brain injury $(2.2 \%, n=1)$, general aging $(2.2 \%, n=1)$, stroke $(2.2 \%, n=1)$, and Parkinson's disease $(2.2 \%, n=1)$. Nearly $33 \%(n=15)$ of caregivers had been told that the patient's condition was terminal, $56.5 \%(n=26)$ had been told that it was not terminal, and $10.9 \%(n$ $=5$ ) were unsure. The largest percentages of caregivers $(34.8 \%, n=16)$ had been providing care for their patients for $2-5$ years, $5-9$ years $(23.9 \%, n=11), 1-2$ years $(21.7 \%, n=10)$, and 10 years or more $(8.7 \%, n=4)$.

Fifty-four percent ( $n=25$ ) of caregivers reported that the patient was aware of the illness and implications, $32.6 \%(n=15)$ of patients were not aware, and $13 \%(n=6)$ of caregivers were not sure whether or not the patient was aware. Eighty-seven percent $(n=40)$ of caregivers were aware of the patient's prognosis and $13 \%(n=6)$ were not sure. Sixty-three percent of caregivers $(n=29)$ were concerned that they may suffer from the same condition as the patient in the future, $23.9 \%(n=11)$ were not concerned, and $13 \%(n=6)$ were not sure.

In the majority of cases $(58.7 \%, n=27)$, patients did not share their feelings and fears about illness. For instance, they did not discuss the possibility of recurrence in case of cancer or the fear of suffering pain. Approximately one third of patients $(34.8 \%, n=16)$ had discussed such feelings, and $4.3 \%(n=2)$ shared those feelings with others but not their caregivers; whereas $2.2 \%(n=1)$ of caregivers were not sure whether patients shared their feelings and fears about illness. 
Likewise, in the majority of cases $(67.4 \%, n=31)$, patients did not share fears about death and dying. For example, they had not discussed the possibility of dying, way of dying, what happens during and after dying, or a desire to avoid experiencing pain during the dying process. Nearly $22 \%$ $(n=10)$ of patients had, however, expressed those concerns, and 2.2\% $(n=1)$ shared those feelings with others but not their caregivers, whereas $8.7 \%(n=4)$ were not sure whether patients shared their feelings about death and dying.

In all cases, patients were provided home care. However, $19.6 \%(n=9)$ of patients were also provided care in a hospital. Sixty-five percent of caregivers $(n=30)$ did not have previous caregiving experience prior to the current patient, whereas $28 \%(n=13)$ had previous experience, and $7 \%(n=$ 3) have also been professional caregivers by occupation (nurse, nurse's aide). Ninety-one percent of caregivers $(n=42)$ received no support, payouts, or benefits for caring for the patient. For example, they did not receive extended absence or leave from their jobs, monetary support from the state, or the patient's insurance payout benefit. Nine percent $(n=4)$ of caregivers received such benefits.

Research Question 1: Can death anxiety predict depression and coping in family caregivers?

Linear regression investigated this research question: The predictor variable was death anxiety, and the outcome variables were depression and coping.

The analysis of variance for the model predicting depression was statistically significant, $F(1,44)=$ $5.44, p=.024 ; R^{2}=.11$. Death anxiety was a significant, negative predictor of depression, $B=-.33, t$ $=-2.33, p=.024$. As death anxiety increased, there was a corresponding decrease in depression.

The analysis of variance for the model predicting coping was also statistically significant, $F(1,44)=$ $6.23, p=.016 ; R^{2}=.124$. Death anxiety was a significant, negative predictor of coping, $B=-.35, t=-$ $2.40, p=.016$. As death anxiety increased, there was a corresponding decrease in coping.

As death anxiety was a significant predictor of depression and coping, and duration of caregiver experience was significantly related to death anxiety, hierarchical multiple regressions were conducted to determine how much variance in death anxiety can be explained by the additive effects of depression, coping, and duration of caregiver experience. Thus, in this analysis, the outcome variable was death anxiety.

In Step 1 of the model, depression significantly and negatively predicted death anxiety, $F(1,44)=$ $5.44 ; B=-.26, p=.02$. In Step 2 of the model, coping significantly and negatively predicted death anxiety, $F(2,43)=5.01 ; B=-.29, p=.047$. The addition of coping to the model added an additional $7.9 \%$ of explained variance. This increase in $R^{2}$ was statistically significant, indicated by a significant $F$ change of $4.18, p=.047$. In Step 3 of the model, duration of caregiver experience was a significant predictor of death anxiety, $F(3,42)=5.72, p=.019$. The addition of duration of caregiver experience to the model added an additional $10.1 \%$ of explained variance. The total variance explained by the model was $29 \%$.

Research Question 2: How do scores on the RCL-FODADS relate to participant demographics (age, gender, education level, number of children, relationship to patient, and duration of caregiver experience)? 
The Pearson $r$ examined the relationship between scores on the RCL-FODADS and participant demographic variables.

There was a significant, positive relationship between death anxiety and duration of caregiver experience, $r(n=46)=.34, p=.02$, two-tailed. As the duration of caregiver experience increased, there was a corresponding increase in death anxiety among caregivers. No other demographic was significantly related to death anxiety.

\section{Discussion}

In Research Question 1, death anxiety was a significant, negative predictor of depression. As death anxiety increased, there was a corresponding decrease in depression. Death anxiety was also a significant, negative predictor of coping: As death anxiety increased, there was a corresponding decrease in coping. This confirms that caregivers fearing death and dying may have a lower ability to cope with caregiving duties, thus suffering more detrimental effects of caregiving. These findings are consistent with the transactional theory of stress (Lazarus \& Folkman, 1984), which leads to the expectation that as stress increased, evidenced in the current study with death anxiety, there was less ability to cope.

In the current study, family caregivers with higher death anxiety scores had lower scores in depression. Previous research on death anxiety and depression is scarce and presents contradictory results; for example, Hintze et al. (1994) found an association between death anxiety and depression; however, the study examined only caregivers of HIV patients. Most previous research on death anxiety included only elderly individuals who were not caregivers. For example, Wagner and Lorion (1984) reported that depression was a significant predictor of death anxiety in a sample of elderly individuals. The sample in the present study was caregivers and was not limited to elderly individuals. Specifically, the mean age of this study's participants was 56 years old. Perhaps the difference in the relationship between death anxiety and depression could be associated with age, and younger individuals may experience death anxiety in the absence of depression; further studies are needed to clarify this finding.

Grief may contribute to the development of depression; however, in family caregivers of nonterminal patients or in family caregivers who avoid accepting the possibility of death of their patients, death anxiety may indeed not be associated with depression. Elizarrarás-Rivas et al. (2010) did not find an association between death anxiety and depression in their sample of family caregivers of patients hospitalized with influenza A(H1N1) in Mexico. Further, according to the Diagnostic and Statistical Manual of Mental Disorders, Fifth Edition (American Psychiatric Association, 2013) depression, as a disorder, is characterized by anhedonia and apathy, which are the loss of ability to experience pleasure and the withdrawal from emotional reactions. This is especially true for patients in severe depression, who are said to have a "nonreactive mood," which means they are unable to get out of their depressed condition. It is possible that depressed caregivers are so withdrawn emotionally that they are unable to experience fear of death or fear of dying for themselves, as well as do not have fears of death and dying of others. Thus, nondepressed caregivers, being emotionally healthy, may be more capable of experiencing death anxiety and other emotional reactions as they become involved in caregiving. This hypothesis requires further investigation in future studies.

Lack of depression in family caregivers, coupled with a lower ability to cope with caregiving duties, suggests the presence of death anxiety as a factor interfering with coping. It may be helpful to screen 
caregivers who have normal scores on depression instruments, yet report coping difficulty with caregiving duties, for death anxiety. Another possible explanation of the finding is the duration of caregiver experience in the sample. Sixty-five percent of caregivers had more than 2 years of caregiver experience. Perhaps they had the opportunity or specific resources to help them deal with their depression in the first years of assuming the caregiving role. Also, in examining the specific coping strategies used most often by the sample (i.e., self-controlling, planful problem solving), it is possible that caregivers utilizing problem-focused coping have a lower chance of becoming depressed versus those who use avoidance or passive coping (Kelly et al., 1999; Redinbaugh et al., 2003).

The correlational analyses investigated by Research Question 2 revealed a significant, positive relationship between death anxiety and duration of caregiver experience. As duration of caregiver experience increased, there was a corresponding increase in death anxiety among caregivers. It is evident that caregiving changes the lives and the future expectations of the family caregivers and may trigger a deep existential reevaluation (Yalom, 1980), as the awareness of one's own mortality and fears of death and dying increase (Bachner et al., 2011). The longer the caregiver experience lasts, the more the caregivers may be immersing themselves into the existential reevaluation and realizing the shortness of life, and the fact that their own life is passing by, thus increasing their own death and dying fears. In other words, the longer the fears of death and dying persist in the caregiver, the more these fears turn into death anxiety.

Additional research of factors that contribute to caregiver burden and specifically death anxiety as a predictor of poor coping are needed to help design interventions for family caregivers. Differential factors within the personal value and belief system of family caregivers may contribute to lower ability to withstand the caregiving strain. The current study found that death anxiety increased with an increase of duration of caregiver experience, which is an important factor to consider when carrying out the caregiver assessment.

Understanding that death anxiety may interfere with coping and developing interventions to help family caregivers deal with death anxiety would allow family caregivers to better cope with their difficult burden and hopefully suffer from less negative effects of caregiving. Contrary to previous research (Lonetto \& Templer, 1986; Neimeyer, 1994; Wagner \& Lorion, 1984), the present study suggested that death anxiety could be present in family caregivers in the absence of depression. This calls for the recommendation that caregivers be assessed for depression, coping efficacy, and death anxiety at the same time, as the absence of depression may not exclude the presence of death anxiety and vice versa.

Generalizability of the present study is important to consider. The study's sample primarily was drawn from family caregivers from the United States; thus, the findings cannot be generalized to a general population of caregivers worldwide. However, the findings could inspire research in other countries to identify similarities and/or differences that could be interpreted in light of different national policies for caregiver support, cultures, and public policy initiatives. In addition, the study did not limit participation to caregivers of patients with specific conditions. The single most common patient diagnosis was cancer (26.1\%), followed by Alzheimer's disease (23.9\%), and dementia (8.7\%). Future studies could focus on specific patient conditions to be able to compare findings across different conditions and identify specific differences between terminal and nonterminal conditions. Future studies could also use other measurement instruments for the variables of death anxiety, depression, and coping to determine if findings would be replicable. Finally, participation in this 
study was limited to caregivers of adult patients. Future studies could examine the relationship among death anxiety, depression, and coping in caregivers of children.

Timely response interventions in support of caregivers are crucial both for safeguarding the fragile health of the caregiver and for the maintenance of uncompromised care for the patient at home. Family caregivers carry out an important function in societies. The rapid increase of the aging population worldwide will continuously raise the number of patients in need of care due to medical conditions or advancing age, and this, in turn, will raise the number of family caregivers. Timely efforts to design effective assessment and intervention programs to support the caregivers will help improve the lives of both the patients and their caregivers, as well as protect caregivers from negative effects with the much needed task of family caregiving.

\section{References}

AARP Public Policy Institute. (2011). Valuing the invaluable: Contributions, costs, and consequences of family caregiving. Retrieved from http://www.aarp.org/relationships/caregiving/info-072011/valuing-the-invaluable.html

American Psychiatric Association. (2013). Diagnostic and statistical manual of mental disorders (5th ed.). Washington, DC: Author.

Bachner, Y. G., \& Carmel, S. (2009). Open communication between caregivers and terminally-ill cancer patients: The role of caregiver's characteristics and situational variables. Health Communication, 24, 524-531. doi:10.1080/10410230903104913

Bachner, Y. G., Davidov, E., \& Carmel, S. (2008). Caregivers' communication with patients about illness and death: Initial validation of a scale. Omega: The Journal of Death and Dying, 57, 381-397. doi:10.2190/OM.57.4.d

Bachner, Y. G., O'Rourke, N., \& Carmel, S. (2011). Fear of death, mortality communication, and psychological distress among secular and religiously observant family caregivers of terminal cancer patients. Death Studies, 35, 163-187. doi:10.1080/07481187.2010.535390

Barr, P., \& Cacciatore, J. (2008). Personal fear of death and grief in bereaved mothers. Death Studies, 32, 445-460. doi:10.1080/07481180801974752

Benton, J. P., Christopher, A. N., \& Walter, M. I. (2007). Death anxiety as a function of aging anxiety. Death Studies, 31, 337-350.

Brazil, K., Bainbridge, D., \& Rodriguez, C. (2010). The stress process in palliative cancer care: A qualitative study on informal caregiving and its implication for the delivery of care. American Journal of Hospice \& Palliative Medicine, 27, 111-116. doi:10.1177/1049909109350176

Carver, C. S., \& Connor-Smith, J. (2010). Personality and coping. Annual Review of Psychology, 61, 679-704. doi:10.1146/annurev.psych.093008.100352

Cassidy, T. (2011). Stress, coping, resilience, and health. In T. J. Devonport (Ed.), Managing stress: From theory to application (pp. 1-40). Hauppauge, NY: Nova Science.

Cassidy, T., \& McLaughlin, M. (2015). Psychological distress of female caregivers of significant others with cancer. Cogent Psychology, 2, 999405. doi:10.1080/23311908.2014.999405 
Couper, J., Bloch, S., Love, A., Macvean, M., Duchesne, G. M., \& Kissane, D. (2006). Psychosocial adjustment of women whose partners have prostate cancer. Psycho-Oncology, 15, 937-953. doi:10.1002/pon.1031

Eaton, W. W., Ybarra, M., Muntaner, C., \& Tien, A. (2004). Center for Epidemiologic Studies Depression Scale: Review and Revision (CESD and CESD-R). In M. E. Maruish (Ed.), Use of psychological testing for treatment planning and outcomes assessment: Volume 3, Instruments for Adults (pp. 363-377). Mahwah, NJ: Lawrence Erlbaum Associates, Inc.

Elizarrarás-Rivas, J., Vargas-Mendoza, J., Mayoral-García, M., Matadamas-Zarate, C., ElizarrarásCruz, A., Taylor, M., \& Agho, K. (2010). Psychological response of family members of patients hospitalised for influenza A/H1N1 in Oaxaca, Mexico. BMC Psychiatry, 10, 104. doi:10.1186/1471-244X-10-104

Family Caregiver Alliance, National Center on Caregiving (FCA). (2011). Fact sheet: Selected caregiver statistics. Retrieved from www.caregiver.org/caregiver

Feifel, H., \& Nagy, V. T. (1980). Death orientation and life-threatening behavior. Journal of Abnormal Psychology, 89, 38-45.

Folkman, S., \& Lazarus, R. S. (2005). Manual for the ways of coping questionnaire. Menlo Park, CA: Mind Garden.

Fortner, B. V., \& Neimeyer, R. A. (1999). Death anxiety in older adults: A quantitative review. Death Studies, 23, 387-411. doi:10.1080/074811899200920

Fortner, B. V., Neimeyer, R. A.,\& Rybarczyk, B. (2000). Correlates of death anxiety in older adults: A comprehensive review. In A. Tomer (Ed.), Death attitudes and the older adult (pp. 95-108). Philadelphia, PA: Brunner-Routledge.

Furer, P., \& Walker, J. R. (2008). Death anxiety: A cognitive-behavioral approach. Journal of Cognitive Psychotherapy, 22, 167-182. doi:10.1891/0889-8391.22.2.167

Glaser, R., \& Kiecolt-Glaser, J. (2005). Stress-induced immune dysfunction: Implications for health. Nature Reviews: Immunology, 5, 243-251. doi:10.1038/nri1571

Harrawood, L. K. (2009-2010). Measuring spirituality, religiosity, and denial in individuals working in funeral service to predict death anxiety. Omega, 60, 129-142.

Hauser, J., \& Kramer, B. (2004). Family caregivers in palliative care. Clinics in Geriatric Medicine, 20, 671. doi:10.1016/j.cger.2004.07.003

Hintze, J., Templer, D. I., Cappelletty, G. G., \& Frederick, W. (1994). Death depression and death anxiety in HIV-infected males. In R. A. Neimeyer (Ed.), Death anxiety handbook: Research, instrumentation, and application (pp. 193-200). New York, NY: Taylor \& Francis.

Holley, C. K., \& Mast, B. T. (2010). Predictors of anticipatory grief in dementia caregivers. Clinical Gerontologist: The Journal of Aging And Mental Health, 33, 223-236. doi:10.1080/07317111003793443

Holtslander, L., \& McMillan, S. (2011). Depressive symptoms, grief, and complicated grief among family caregivers of patients with advanced cancer three months into bereavement. Oncology Nursing Forum, 38, 60-65. doi:10.1188/11.ONF.60-65 
Kelly, B., Edwards, P., Synott, R., Neil, C., Baillie, R., \& Battistutta, D. (1999). Predictors of bereavement outcome for family carers of cancer patients. Psycho-Oncology, 8, 237-249. doi:10.1002/(SICI) 1099-1611

Kieffer, K. M., \& MacDonald, G. (2011). Exploring factors that affect score reliability and variability: In the Ways of Coping Questionnaire reliability coefficients: A meta-analytic reliability generalization study. Journal of Individual Differences, 32, 26-38. doi:10.1027/16140001/a000031

Kuhl, D. (2005). Facing death: Embracing life. Canadian Family Physician - Le Medecin de famille canadien, 51, 1606-1608.

Lazarus, R. S., \& Folkman, S. (1984). Stress, appraisal and coping. New York, NY: Springer.

Lester, D. (1994). The Collett-Lester Fear of Death Scale. In R. A. Neimeyer, (Ed.), Death anxiety handbook: Research, instrumentation, and application (pp. 45-59). New York, NY: Taylor \& Francis.

Lonetto, R., \& Templer, D. I. (1986). Death anxiety. New York, NY: Hemisphere.

Lovell, B., \& Wetherell, M. A. (2011). The cost of caregiving: Endocrine and immune implications in elderly and non elderly caregivers. Neuroscience and Biobehavioral Reviews, 35, 1342-1352. doi:10.1016/j.neubiorev.2011.02.007

Missler, M., Stroebe, M., Geurtsen, L., Mastenbroek, M., Chmoun, S., \& van der Houwen, K. (2011). Exploring death anxiety among elderly people: a literature review and empirical investigation. Omega, 64, 357-379. doi:10.2190/OM.64.4.e

Moore, C. C., \& Williamson, J. B. (2003). The universal fear of death and cultural response. In C. D. Bryant (Ed.), Handbook of death and dying. Thousand Oaks, CA: Sage.

Murphy, N. A., Christian, B., Caplin, D. A., \& Young, P. C. (2007). The health of caregivers for children with disabilities: Caregiver perspectives. Child: Care, Health and Development, 33, 180-187. doi:10.1111/j.1365-2214.2006.00644.x

National Alliance for Caregiving \& AARP. (2009). Caregiving in the U.S. Bethesda, MD: National Alliance for Caregiving. Retrieved from www.caregiving.org/pdf/research/Caregiving_in_the_US_2009_full_report.pdf

Neimeyer, R. A. (1994). Death anxiety handbook. New York, NY: Taylor \& Francis Group.

Neimeyer, R. A., Wittkowski, J., \& Moser, R. P. (2004). Psychological research on death attitudes: An overview and evaluation. Death Studies, 28, 309-340. doi:10.1080/07481180490432324

O'Gorman, S. M. (1998). Death and dying in contemporary society: An evaluation of current attitudes and the rituals associated with death and dying and their relevance to recent understandings of health and healing. Journal of Advanced Nursing, 27, 1127-1135. doi:10.1046/j.13652648.1998.00659.x

Pinquart, M., \& Sorensen, S. (2003). Differences between caregivers and noncaregivers in psychological health and physical health: A meta-analysis. Psychology and Aging, 18, 250267. doi:10.1037/0882-7974.18.2.250

Pinquart, M., \& Sorensen, S. (2011). Spouses, adult children, and children-in-law as caregivers of older adults: A meta-analytic comparison. Psychology and Aging, 26, 1-14. doi:10.1037/a0021863 
Radloff, L. S. (1977). The CES-D Scale: A self-report depression scale for research in the general population. Applied Psychological Measurement, 1, 385-401.

doi:10.1177/014662167700100306

Raggia, A., Tascab, D., Paneraib, S., Neria, W., \& Ferrib, R. (2015). The burden of distress and related coping processes in family caregivers of patients with Alzheimer's disease living in the community. Journal of the Neurological Sciences, 358, 77-81.

Redinbaugh, E. M., Baum, A., Tarbell, S., \& Arnold, R. (2003). End-of-life caregiving: What helps family caregivers cope? Journal of Palliative Medicine, 6, 901-909. doi:10.1089/109662103322654785

Rivera, H. R. (2009). Depression symptoms in cancer caregivers. Clinical Journal of Oncology Nursing, 13, 195-202. doi:10.1188/09.CJON.195.202

Schulz, R., \& Beach, S. R. (1999). Caregiving as a risk factor for mortality: The Caregiver Health Effects Study. JAMA: Journal of the American Medical Association, 282, 2215-2219. doi:10.1001/jama.282.23.2215

Sharif Nia, H., Lehto, R. H., Ebadi, A., \& Peyrovi, H. (2016). Death anxiety among nurses and health care professionals: A review article. International Journal of Community Based Nursing Midwifery, 4, 2-10.

Smith, G., Williamson, G., Schulz, R., \& Miller, S. (2011). Depression and quality of care: A longitudinal investigation of caregiving stressors. Psychology and Aging, 26, 584-591. doi:10.1037/a0022263

Tew, E. S., Naismith, S. L., Pereira, M., \& Lewis, S. J. (2013). Quality of life in Parkinson's disease caregivers: The contribution of personality traits. BioMed Research International, 2013, 151872. doi:10.1155/2013/151872

Vedhara, K., \& Irwin, M. R. (2005). Human psychoneuroimmunology. New York, NY: Oxford University Press.

Vitaliano, P. P., \& Katon, W. J. (2006). Effects of stress on family caregivers: Recognition and management. Psychiatric Times, 23, 24-28.

Wagner, K. D., \& Lorion, R. P. (1984). Correlates of death anxiety in elderly persons. Journal of Clinical Psychology, 40, 1235-1241. doi:10.1002/1097-4679(198409)40:5<1235::AIDJCLP2270400519>3.0.CO;2-P

Waldrop, D., Kramer, B., Skretny, J., Milch, R., \& Finn, W. (2005). Final transitions: Family caregiving at the end of life. Journal of Palliative Medicine, 8, 623-638. doi:10.1089/jpm.2005.8.623

Wink, P. (2006). Who is afraid of death? Religiousness, spirituality, and death anxiety in late adulthood. Journal of Religion, Spirituality \& Aging, 18, 93-110. doi:10.1300/J496v18n02_08

World Health Organization. (2010). Ageing and life course. Retrieved from http://www.who.int/ageing/en

Yalom, I. D. (1980). Existential psychotherapy. New York, NY: Basic Books.

Zhang, A. Y., \& Siminoff, L. A. (2003). Silence and cancer: Why do families and patients fail to communicate? Health Communication, 15, 415-429. doi:10.1207/S15327027HC1504_03 
The Journal of Social, Behavioral, and Health Sciences is an open-access, peer-reviewed, online interdisciplinary journal focusing on research findings that address contemporary national and international issues. Its objectives are to (a) encourage dialogue between scholars and practitioners in the social, behavioral, and health sciences that fosters the integration of research with practice; (b) promote innovative models of interdisciplinary collaboration among the social, behavioral, and health sciences that address complex social problems; and (c) inform the relationship between practice and research in the social, behavioral, and health sciences.

Walden University Publishing: http://www.publishing.waldenu.edu 